\title{
Financiamento da Educação: Gestão \\ Democrática dos Recursos Financeiros \\ Públicos em Educação
}

\author{
José Carlos de Araújo Melchior
}

Universidade de São Paulo (USP)

Aborda a gestão democrática dos recursos públicos no Brasil, sob a perspectiva do processo administrativo, envolvendo o planejamento, a execução e o controle social dos recursos financeiros públicos. Pretende ainda ampliar a concepção de que a gestão democrática se dá pela via exclusiva da participação dos interessados nos órgãos decisórios. São enfocadas alternativas que podem levar qualquer cidadão a participar desse processo em educação e, por extensão, nos demais setores de atividades exercidas pelo poder público, fornecendo instrumentos para uma intervenção na receita e na despesa do setor público encarregado de gerir os recursos financeiros alocados para a educação. $O$ trabalho divide-se em cinco partes: 1) a experiência no Estado de São Paulo; 2) a sistemática do planejamento público; 3) a sistemática da execução orçamentária; 4) o controle social dos recursos financeiros públicos e 5) as conclusões.

\section{Introdução}

Este trabalho trata da gestão democrática dos recursos públicos no Brasil, a qual será tratada sob a perspectiva do processo administrativo, envolvendo o planejamento, a execução e o controle social dos recursos financeiros públicos. A análise que se faz tem por suporte toda uma legislação geral, escolar e orçamentária, que dá uma característica compulsória aos assuntos tratados. Apesar de o trabalho abordar algumas situações específicas do Estado de São Paulo, na maior parte das vezes a validade dos resultados atinge a União, os demais Estados, o Distrito Federal e os municípios.

E uma tentativa de contribuir para o aprofundamento da idéia de gestão democrática dos recursos financeiros, e de discutir uma experiência vivida pelo Estado de São Paulo, que pode abrir 
novos caminhos para a União e demais Estados da Federação. E, ao mesmo tempo, uma tentativa de contribuir para que indivíduos, comissões, órgãos ou associações de classe que se interessam ou estão envolvidos no processo de gestão dos recursos públicos em educação tomem conhecimento de algumas alternativas que poderão contribuir para o aperfeiçoamento da administração dos recursos financeiros públicos em educação.

Finalmente, este trabalho pretende ampliar a concepção de que a gestão democrática se dá pela via exclusiva da participação dos interessados nos órgãos decisórios. Aqui são expostas alternativas que podem levar qualquer cidadão do povo a participar do processo de gestão dos recursos públicos em educação e, por extensão, nos demais setores de atividades exercidas pelo poder público.

A idéia central que o orienta é a de que informações nestas diferentes perspectivas fornecem a indivíduos ou grupos, organizados ou não, os instrumentos para uma intervenção na receita e na despesa do setor público encarregado de gerir os recursos financeiros alocados para a educação.

A experiência do Estado de São Paulo

Em agosto de 1989, o governo do Estado de São Paulo deu início a um processo induzido de descentralização na área da educação. Como o governador Orestes Quércia havia sido eleito com a bandeira da municipalização, a este processo deu-se o nome de Municipalização do Ensino.

Anteriormente já havia um processo de descentralização na área da educação. No entanto, era um processo fragmentado, difuso e esparso, constituído de ações isoladas, conforme as necessidades dos municípios e as disponibilidades da Secretaria de Estado da Educação. Na gestão governamental de Franco Montoro, as ações de descentralização foram intensificadas e, em agosto de 1989, cerca de cinco mil convênios estavam em andamento, firmados entre Estado e municípios, quase todos com problemas de execução e controle. 
O que o governo do Estado fez, a partir de agosto de 1989, foi transformar ações isoladas numa política integrada, que passou a ser denominada de Municipalização do Ensino. A nova política abrangia 11 ações. Incluía as anteriores e abrangia ações ainda inexistentes na esfera da Secretaria da Educação. Ao incluir as já existentes, procurou extirpar todos os problemas e erros dos antigos convênios.

Naquele momento, em agosto de 1989, o Estado possuía 571 municípios. O objetivo do governador era chegar ao fim do seu mandato com a inclusão de 300 municípios no Programa de Municipalização. Por adesão voluntária, em novembro de 1990, o programa já havia firmado convênios com 346 municípios, havendo cerca de mais 100 nele querendo entrar.

Na esfera estadual, o Programa de Municipalização consta do Decreto $\mathrm{n}^{\mathrm{s}}$ 30.375, publicado no Diário Oficial do Estado de São Paulo, em 14/9/89, que delega ao secretário da Educação o poder de firmar convênios com os prefeitos dos municípios. Como parte integrante do decreto, publicou-se na mesma data o modelo de convênio único que seria assinado com o município e a exposição de motivos que explicava as razões ou bases teóricas do programa que se pretendia implantar. A partir do convênio único, poderiam ser assinados termos aditivos que abrangessem as áreas de construções escolares, merenda, material de apoio didático, aperfeiçoamento de pessoal, apoio a eventos escolares, transporte escolar, integração do currículo à realidade da escola e assistência ao aluno. O município, para aderir voluntariamente, deveria ter uma lei municipal que autorizasse o prefeito a entrar no programa, assinando, de início, o convênio único e, posteriormente, os termos aditivos.

O Programa de Municipalização, que começou a ser implantado na gestão de Wagner Rossi na Secretaria da Educação, posteriormente ficou estagnado na gestão de José Goldemberg e, na gestão de Carlos Estevan Martins, sofreu um novo impulso em seu aspecto de política de descentralização. Em 24/9/90 foi baixado o Decreto $n^{0}$ 32.392, que autoriza o secretário da Educação a celebrar Termo de Cooperação Intergovernamental (TCI) com 
municípios do Estado de São Paulo. O TCI faz parte do decreto e visa construir e equipar prédios escolares, em terrenos doados pelos municípios, destinando-os a estes últimos, para implantação de escolas de ensino fundamental criadas e administradas exclusivamente pela esfera municipal. E o início da efetiva implantação e/ou do desenvolvimento dos sistemas municipais de ensino, prevista na Constituição Federal de 1988. Com essa medida criaram-se as condições para a intensificação do processo de descentralização da educação no Estado de São Paulo, através da ação, da colaboração e da cooperação entre Estado e município, visando garantir a melhoria da qualidade do ensino e a criação de melhores condições para que os alunos tenham o acesso, a permanência e a progressão no sistema público de ensino.

De maior interesse, contudo, para os fins deste trabalho, foi a criação da Comissão de Educação do Município (CEM). Ao assinar o convênio único, o município obrigava-se a "tomar providências para a instalação, o funcionamento e o desenvolvimento das atividades da Comissão de Educação do Município, bem como participar ativamente de seus trabalhos e colaborar para o seu desempenho eficiente". Os objetivos da CEM eram identificar problemas, estabelecer prioridades e propor soluções.

O critério de constituição das CEMs foi a pluralidade de representação, sendo uma representação fixa e uma variável, de acordo com as forças atuantes da comunidade.

A parte fixa foi constituída com os seguintes representantes:

a) o prefeito e/ou o dirigente municipal de educação;

b) um representante dos vereadores, eleito por seus

pares;

c) um representante da Secretaria da Educação do Estado, que será o delegado de ensino, no caso do município ser a sede da Delegacia de Ensino, ou um supervisor de ensino, por aquele indicado, nos demais casos;

d) um representante dos diretores de escolas, eleito por seus pares; 
pares;

e) um representante dos professores, eleito por seus

f) um secretário de escola, eleito pelos funcionários da escola;

g) um representante dos pais, eleito pelas Associações de Pais e Mestres (APMs).

A parte variável da composição das Comissões de Educação dos Municípios terá um mínimo de três e um máximo de cinco representantes de segmentos atuantes da sociedade local. Os representantes desses segmentos serão apontados pelos componentes da representação fixa da Comissão de Educação do Município.

Deu-se um prazo de sessenta dias, a contar da data da assinatura do convênio, para o município providenciar a criação, a constituição e a instalação da Comissão de Educação do Município, a qual deverá ter Regimento próprio, e enviar, trimestralmente, relatório de suas atividades, dando destaque à avaliação e aos problemas de execução do convênio.

O Programa de Municipalização do Ensino está em desenvolvimento, tendo atingido três ações prioritárias: construção de salas de aulas, reforma e ampliação de prédios escolares e fornecimento de material didático de apoio às atividades escolares, principalmente aparelhos audiovisuais.

Além de dar início a um processo integrado e ordenado de ações descentralizadas, em regime de colaboração entre Estado e município, o programa, ao criar as Comissões de Educação do Município, procurou equacionar uma questão vital para os educadores: a questão da representação da comunidade - uma questão vital para os educadores, os políticos, os partidos, e para a população, bem como para o funcionamento da democracia participativa, que não se circunscreve somente à participação delegada mediante a eleição dos representantes dos Poderes Executivo e Legislativo. Aos poucos, foi se desenvolvendo a idéia de que uma nação compõe-se de governo e sociedade civil, não bastando somente a participação, por delegação, do governo nas decisões referentes ao destino do País. Ao contrário, foi se desenvolvendo a idéia de que mais importante que o governo é a organização da 
sociedade civil, seja participando dos órgãos governamentais, seja criando suas associações próprias, ou participando de situações mistas nas quais governo e sociedade estejam representados. Nas democracias, os controles internos desenvolvidos pelo governo e sua burocracia devem ser complementados pelos controles externos, compostos pela representação popular delegada e pela sociedade civil. É desta última que nasce o controle social da aplicação dos recursos financeiros públicos.

De modo simples, mas eficaz, é a Comissão de Educação do Município que passa a ser o instrumento fundamental do controle social dos recursos financeiros aplicados à educação pelo Estado e pelo município. As CEMs funcionam ao lado da burocracia, colaborando na agilização da identificação e na solução dos problemas das redes estadual e municipal de ensino. Seus componentes envolvem os poderes públicos estadual e municipal e as pessoas que representam os segmentos envolvidos direta $\mathrm{e}$ indiretamente no ensino. $\mathrm{O}$ critério de representatividade dos segmentos envolvidos significa que as CEMs não são compostas por pessoas especializadas em educação, mas que lá estão para manifestar o que pensam os diversos segmentos em relação aos problemas educacionais. Como os segmentos representam interesses e pontos de vista diferentes, a divergência e o conflito passam a ser naturais e normais. É a regra que orienta o sistema democrático: institucionalizar o conflito, buscando as soluções de consenso e/ou de maiorias, respeitados os interesses da minoria, que também participa do processo e que pode influir na tomada de decisão final.

O funcionamento das CEMs não é condicionado por receitas. A CEM é o fator fundamental de um processo de conscientização e participação da sociedade local nos problemas da educação. Não havendo receitas e nem regras preestabelecidas em relação aos limites de funcionamento das CEMs, sua atuação, em grande parte, vai depender do interesse, competência e capacidade de liderança de seus membros. Há um espaço a ser ocupado por disposições do convênio único e por meio de cada ação desenvolvida que é transcrita nos termos aditivos. Além disso, há uma 
zona de liberdade, um espaço não determinado, cuja existência vai depender da capacidade dos membros da CEM, seja sugerindo, criticando, controlando ou avaliando a educação, concretamente, em suas manifestações locais.

Na prática, nós temos CEMs que vão desde as mais atuantes e produtivas até aquelas que não acreditam no seu poder de colaborar e de pressionar em benefício da educação local. $\mathrm{E}$ isto tem que ser visto como um processo normal, que depende da educação de seus membros e da constante valorização de sua atuação por parte das autoridades, incentivando-as com reforços positivos, tanto a curto como a médio e a longo prazo. Detonado um processo social dessa magnitude, resta somente ter a esperança de que os envolvidos nele saibam valorizá-lo para que não se perca a oportunidade de fazer valer um dos princípios mais buscados nos sistemas democráticos, que é o da participação nas decisões que podem afetar as nossas vidas.

O que será visto a seguir são questões que podem ajudar a tornar essa participação mais dinâmica e eficaz em prol da educação.

\section{A sistemática do planejamento público}

Em princípio, tudo o que será visto aqui alcança as esferas públicas da União, dos Estados e dos municípios. No caso do Estado de São Paulo, os mesmos termos da Constituição Federal foram inscritos em sua Constituição Estadual.

A nova sistemática do planejamento público, inscrita na Constituição Federal de 1988, prevê três leis, de iniciativa do Poder Executivo, e abrange três instrumentos distintos, mas complementares e integrados, que são os seguintes: 1) o plano plurianual; 2) as diretrizes orçamentárias; e 3) os orçamentos anuais.

É, portanto, uma sistemática de planejamento orçamentário imperativa e obrigatória, porque aprovada como Lei (Art. 165 da Constituição Federal). Por outro lado, há uma sistemática paralela, condicionada à descrita, e que abrange planos e programas nacionais, regionais e setoriais. No caso da educação, há obrigato- 
riedade de se elaborar planos em níveis nacional, estadual e municipal.

Portanto, os planos de educação terão que ser elaborados em consonância com o orçamento plurianual, o mesmo acontecendo com a Lei de Diretrizes Orçamentárias e com o orçamento anual. O orçamento plurianual é a peça central do sistema de planejamento e condiciona todos os demais instrumentos. Suponhamos que o presidente, o governador ou o prefeito tenha sido eleito com um programa de governo. No começo, esse programa irá sofrer ajustes; só posteriormente é que irá condicionar o orçamento plurianual. Este, por sua vez, será complementado pela Lei de Diretrizes Orçamentárias e pelo orçamento anual. O programa de governo poderá, então, transformar-se no plano de governo, que, por sua vez, poderá se desdobrar em planos nacionais, regionais e setoriais, conforme o alcance da esfera pública envolvida seja nacional, estadual ou municipal.

O orçamento plurianual visa estabelecer as diretrizes, os objetivos e as metas da administração pública no que diz respeito aos programas de duração continuada, isto é, aos que ultrapassam a duração de mais de um ano. Antigamente, o orçamento plurianual era denominado de orçamento de capital, porque era restrito às despesas de capital. Atualmente, o orçamento plurianual abrange as despesas de capital e outras delas decorrentes, isto é, os seus reflexos. Não basta, por exemplo, prever a construção de um prédio para uma escola; há que equipá-la e fazê-la funcionar, e daí decorrem despesas complementares que também devem ser previstas.

A Lei de Diretrizes Orçamentárias compreende as metas e as prioridades da administração pública, orientando a Lei Orçamentária Anual, incluindo as despesas de capital para o exercício subseqüente e as modificações da legislação tributária, e fazendo a previsão da política de aplicação de recursos financeiros das agências oficiais de fomento.

A Lei Orçamentária Anual compreende:

a) o orçamento fiscal, seus fundos, órgãos e entidades da administração direta e da indireta, inclusive fundações; 
b) o orçamento de investimento das empresas em que o poder público, direta ou indiretamente, detenha a maioria do capital com direito a voto;

c) o orçamento da seguridade social, abrangendo todas as entidades e órgãos a ela vinculados.

Além disso, está prevista uma Lei Complementar Financeira que disporá sobre o exercício financeiro, a vigência, os prazos, a elaboração e a organização do orçamento plurianual da Lei de Diretrizes Orçamentárias e da Lei Orçamentária Anual, estabelecendo normas de gestão financeira e patrimonial da administração direta e da indireta, bem como condições para a instituição e o funcionamento dos fundos.

Mas, o que mais interessa à população, de modo geral, é a Lei Orçamentária Anual, porque ela é a lei que sintetiza e integra todas as demais leis que regem o planejamento orçamentário, isto é, o orçamento plurianual, a Lei de Diretrizes Orçamentárias e a Lei Complementar Financeira.

Até por volta de 1940, os orçamentos não eram padronizados. Disso decorre que comparar orçamentos da União, Estados e municípios, antes de 1940, significa comparar coisas diferentes. Foi a partir de 1939, com o Código de Contabilidade Pública, que ocorreu a unificação e a padronização da terminologia orçamentária. No entanto, esse código acabou expressando a linguagem do Direito, já que o Brasil, até 1964, era o país dos bacharéis. A partir de 1964, com o domínio dos economistas, foi aprovada a Lei $n^{\circ} 4.320$, de 17/3/1964, que estatuiu as "Normas gerais de Direito Financeiro para elaboração e controle dos orçamentos e balanços da União, dos Estados, dos municípios e do Distrito Federal". Assim como a educação é regida pela Lei de Diretrizes e Bases da Educação Nacional, os orçamentos e os balanços públicos são regidos pela Lei $n^{0} 4.320$.

A Lei $\mathrm{n}^{0} 4.320$ obriga as esferas públicas a elaborar os orçamentos, obedecendo a diversas classificações, a saber: a) por órgão; b) por funções; c) por elemento econômico; d) por programas.

$\mathrm{O}$ avanço maior da Lei $\mathrm{n}^{0} 4.320$ diz respeito à classificação por programas. Assim sendo, ela procurou incorporar a técni- 
ca orçamentária mais evoluída na época, adotada pelos países mais desenvolvidos.

A técnica orçamentária evolui, então, procurando preencher lacunas e responder a questões colocadas pelos especialistas. Assim, a técnica do orçamento-programa procura situar os programas onde estão sendo gastos os recursos. Por exemplo, a classificação por órgãos nos diz que a Secretaria de Estado da Educação vai ter um determinado dispêndio. A classificação por função já alarga a concepção de ensino, realizado pelo órgão próprio, e classifica na função educação despesas que estão sendo efetivadas por outras secretarias, que não a da Educação, mas que são despesas ditas de educação. A classificação econômica, que deve ser feita por elemento econômico desdobrado em subelementos, item e sub-itens, visa detalhar a visão econômica, desagregando-a, como por exemplo:

1. Despesas correntes

1.1. Despesas de custeio

1.1.1. Pessoal

1.1.2. Material de consumo

1.1.3. Serviços de terceiros e encargos

1.1.4. Diversas despesas de custeio.

Pelas classificações anteriores, ficamos sabendo que vai haver um dispêndio no órgão (Secretaria da Educação), na função (educação praticada também em outras secretarias), no elemento econômico (despesas de pessoal, por exemplo), mas não sabemos ainda porque ou em que se vai gastar. A classificação por programas - que se desdobram em programas, projetos e atividades, que, por sua vez, se desdobram em subprogramas, subprojetos e subatividades - visa situar o objetivo que se vai ter com a despesa. É também uma técnica que visa a um maior detalhamento dessa despesa.

Em alguns países, a técnica orçamentária já evoluiu para o orçamento de performance ou desempenho, visando avaliar de forma mais objetiva os dispêndios públicos. Assim, em todas as funções exercidas pelo poder público, são utilizados determinados parâmetros comumente aceitos. Em educação, por exemplo, o cus- 
to-aluno; em saneamento, o custo do metro quadrado; em ruas e estradas, o metro ou o quilômetro quadrado construído; em hospitais, o custo-leito etc. No caso da educação e seu parâmetro, o custo-aluno, se houver variação, a mais ou a menos, há a possibilidade de se aferir as causas da variação e de se concluir sobre os prós ou os contras em relação a determinado dispêndio. Há, ainda, a possibilidade de se corrigir desvios na execução orçamentária anual e de se tentar eliminar erros no próximo orçamento.

Em outros países, a técnica orçamentária evoluiu para o orçamento base-zero. Esta técnica visa sanar a deficiência de se alocar recursos para uma função em virtude de fatores históricos não muito racionais. Assim dá-se uma fatia do bolo orçamentário para a educação, sem uma análise mais profunda das justificativas de seus gastos. Dá-se porque anteriormente se dava. A técnica do orçamento base-zero obriga a uma análise exaustiva dos dispêndios com justificativas para tudo, com prioridades nítidas e claras. Em princípio, nenhuma função exercida pelo poder público recebe recursos sem justificativas, que deverão ser aprovadas e compatibilizadas pelos órgãos superiores de elaboração orçamentária. Em princípio, então, o que cada órgão recebe é zero de recursos; daí o nome de orçamento base-zero. Somente diante de exaustiva e detalhada justificativa é que os recursos serão alocados. Para isso, usa-se a técnica de exigir três tipos de orçamentos: a) o de manutenção; b) o de redução; c) o de expansão.

Começa-se a discutir o orçamento de redução. Aceito este, passa-se para o de manutenção, isto é, para o mesmo nível de recursos do ano anterior. Se aceito, passa-se à discussão e à justificativa do orçamento de expansão. O certo é que esta técnica obriga a uma reflexão aprofundada dos dispêndios públicos.

A adoção de qualquer uma dessas técnicas não significa o abandono das demais; são técnicas que se complementam e se integram no orçamento. O Brasil, contudo, ainda está engatinhando nessas técnicas de planejamento orçamentário, em função de pessoal não-habilitado. $\mathrm{O}$ esforço qualitativo em relação ao orçamento requer dispêndios financeiros na formação de pessoal habilitado. Mesmo na elaboração de orçamentoprograma, de cum- 
primento obrigatório, a nossa capacidade de planejar ainda deixa muito a desejar. No caso do orçamento base-zero, o Estado de São Paulo já efetivou a experiência, mas também sem atingir sua plena eficácia. Um orçamento qualitativamente inferior contribui para seccionar a possibilidade de plenitude na prática democrática de bem gerir os recursos públicos.

Quanto mais desagregado e detalhado for um orçamento, maior a possibilidade de controle da sociedade sobre os recursos públicos que, conforme o próprio nome expressa, são recursos do povo. O nível de detalhamento do orçamento-programa ainda não é suficiente para um efetivo controle social. Resta aos que se interessam por essa questão a alternativa de recorrer aos órgãos de elaboração orçamentária que possuem as condições para desagregar os dados do orçamento e, portanto, facilitar o controle de sua execução. A forma sintética como o orçamento é levado ao público dificulta seu controle até mesmo pelos especialistas. Uma das funções dos grupos organizados da sociedade civil é a de exigir a desagregação daquela forma. Qualquer cidadão tem o direito de ficar sabendo onde o poder público vai gastar o dinheiro da população.

Em países mais desenvolvidos, o governante eleito envia para os órgãos de elaboração orçamentária as prioridades de seu governo, que têm por suporte as promessas pré-eleitorais. É a forma encontrada para manter o vínculo delegação-povo e a aplicação de recursos financeiros. Aprovados os orçamentos, os grupos da sociedade civil e a imprensa procuram adquirir cópia dos mesmos, dando-lhes publicidade e passando a controlar os dispêndios do governo, evitando que este malbarate os recursos da população ou comece a fazer políticas pessoais não constantes do orçamento.

Uma questão-chave na elaboração orçamentária diz respeito à previsão da receita que vai ser arrecadada. É a partir da previsão da receita que se chega às disponibilidades reais e que se pode, então, prever as despesas, isto é, o atendimento às necessidades. A receita, além de outros fatores, é condicionada pelo nível da atividade econômica e pelo índice de inflação na economia. No entanto, fica muito difícil prever, com exatidão, com um 
ano de antecedência, qual vai ser a aceleração ou desaceleração do ritmo das atividades econômicas e da inflação. A média da receita dos três últimos anos não funciona adequadamente em países de bruscas guinadas em planos econômicos e inflação acelerada, como é o caso do Brasil. A Lei $n^{\circ} 4.320$ exige uma análise do horizonte da política econômica que vai vigorar no exercício financeiro de um orçamento. Mas isso também é muito difícil, porque decorre de fatores internos e externos. Quanto maior for a esfera pública, maior o número de fatores intervenientes e, portanto, mais complexa e difícil se torna a previsão da receita.

$\mathrm{Na}$ prática resulta aquilo que já se tornou praxe afirmar: o orçamento público é uma peça de ficção. Em estudo que realizamos, ficou demonstrado que quem mais erra na previsão da receita é a União, em cerca de 50\%; depois, os Estados e, por último, os municípios. Em outras palavras, os orçamentos são subestimados em sua receita. A complexidade da estimativa da receita e a instabilidade contínua da economia levam os governantes a fazer estimativas conservadoras, isto é, subestimativas. Alia-se à complexidade da estimativa da receita, no caso brasileiro, a política pessoal ou politicagem dos governantes. É mais vantajoso para os governantes subestimar a receita, porque o excesso de arrecadação, que virá depois, permitirá a eles fazer seus programas e projetos especiais, com menos controle por parte da representação popular. Quanto há excesso de arrecadação, o governante busca aprovar créditos adicionais. Fica muito mais fácil, durante o ano, aprovar diversos créditos adicionais, onde o sistema de controle dos representantes do povo (vereadores, deputados estaduais ou membros do Congresso Nacional) é mais elástico e menos vigilante, do que o crédito utilizado por ocasião da aprovação do orçamento público. Fica muito mais fácil o Executivo barganhar com o Legislativo um pequeno crédito adicional do que a massa de recursos envolvidos no orçamento. São os créditos adicionais que permitem a execução de políticas pessoais e fragmentárias que solapam o planejamento mais globalizado do orçamento. Portanto, à sociedade compete ficar de olho vigilante tanto em relação à estimativa da receita quanto em relação aos créditos adicionais que 
se verificam durante o ano. Isto significa que é preciso maior atenção para com a elaboração e a execução do orçamento.

No entanto, a questão de fundo, a mais substantiva, que envolve o orçamento e a educação, diz respeito à vinculação constitucional de recursos dos impostos para a educação. A União, os Estados, o Distrito Federal e os municípios são obrigados a aplicar, no mínimo, parte da receita de impostos na manutenção e desenvolvimento do ensino. Os dispêndios mínimos obrigatórios são os seguintes: a) União - 18\%; b) Estados - 25\%; c) Distrito Federal - 25\%; d) Municípios - 25\%. São mínimos referentes à receita de impostos e não a toda receita tributária (que é o conjunto de impostos, taxas e contribuições), e muito menos à receita geral (que é o conjunto das receitas tributárias, industrial, patrimonial etc). Por outro lado, os recursos vinculados dos impostos só podem ser aplicados na manutenção e no desenvolvimento do ensino, o que exclui a função educação, que tem maior abrangência e que diz respeito ao sistema de ensino submetido à legislação comum da Lei de Diretrizes e Bases da Educação Nacional. Foram tantos os desvios de concepção do que significa manutenção e desenvolvimento do ensino, que o Congresso foi obrigado a disciplinar a questão pela Lei $\mathrm{n}^{\circ} 7.385 / 85$, que regulamentou a Emenda Calmon. Como a Constituição Federal de 1988 manteve o espírito e a letra da Emenda Calmon, a Lei $\mathrm{n}^{\circ} 7.348 / 85$, de $24 / 7 / 85$, continua em vigor e tem orientado os Tribunais de Contas no controle e aplicação obrigatória de recursos financeiros em educação.

A Lei $n^{\circ} 7.348 / 85$ regulamenta algumas questões da receita e outras das despesas, como veremos mais adiante. Por outro lado, obriga todos os órgãos envolvidos com as diversas fases de elaboração, execução e controle do orçamento a se reajustarem para que a lei possa ser cumprida. Na prática, isso significa que o orçamento anual teve que assumir um novo tipo de classificação, isto é, aquele referente à educação, e meio pelo qual se cumprem a vinculação obrigatória e os dispositivos específicos ligados à receita e à despesa com aquilo que se entende por manutenção e desenvolvimento do ensino. Em termos operacionais, resulta 
que, no orçamento anual da União, há um quadro especifico que diz respeito ao cumprimento das disposições legais, constitucionais e regulamentares que se referem: a) ao dispêndio mínimo obrigatório em ensino; b) à receita de impostos estimada; c) à despesa com manutenção e desenvolvimento do ensino, desagregada por programas.

Este quadro especifico adotado pela União também é obrigatório para os Estados, o Distrito Federal e os municípios, pois é a forma mais simples de demonstrar o cumprimento dos dispositivos legais referentes ao assunto, no plano do orçamento. Portanto, este quadro especifico fornece as condições mínimas para o controle inicial da aplicação mínima de recursos financeiros em educação.

As principais questões que envolvem a elaboração desse quadro demonstrativo são as seguintes:

a) A receita de impostos deve abranger as estimativas de impostos próprios e impostos transferidos. Os impostos arrecada dos por uma esfera pública, e depois transferidos às outras esfe ras, devem entrar como receita na esfera que recebeu a transfe rência. A União arrecada alguns impostos que são transferidos para os Estados, o Distrito Federal e os municípios. O mesmo acontece com os Estados, que arrecadam alguns impostos e os transferem para os seus municípios. Portanto, receita é o conjunto de impostos próprios ou privativos mais os recursos de impostos recebidos por meio de transferências.

b) $\mathrm{O}$ dispêndio mínimo obrigatório refere-se exclusiva mente a impostos. Recursos outros, oriundos de taxas, contribui ções, doações e outros tipos de receita, devem ser excluídos da sis temática obrigatória. Isto é importante porque a educação recebe recursos fora do sistema de impostos, como, por exemplo, os do salário-educação, que é uma contribuição social, figura tributária que não tem nenhuma relação com a concepção de imposto. Isto acontecia com os recursos do Fundo de Apoio ao Desenvolvimento Social (Finsocial), que era outra contribuição social. Atividades em que o poder público era concessionário, como, por exemplo, as loterias, também destinavam parte dos seus recursos para a edu- 
cação, por meio do Finsocial, embora esses recursos não fossem impostos. $\mathrm{O}$ mesmo se dá com os recursos de incentivos fiscais destinados à alfabetização.

c) Observar que, pela Lei $n^{0} 7.348$, de 24/7/85, somente podem ser consideradas despesas com manutenção e desenvolvimento do ensino as que se referem a recursos financeiros aplicados em: bens e serviços de ensino; levantamentos estatísticos, estudos e pesquisas somente quando ligados ao ensino; custeio de operações de crédito para financiar o ensino; bolsas de estudos; pessoal inativo ligado ao ensino; colégios militares de $1^{\circ}$ e $2^{\circ}$ graus.

Portanto, devem ser excluídas das despesas ditas de manutenção e desenvolvimento do ensino as que se referem a: pesquisas não vinculadas ao ensino; subvenções a entidades assistenciais e culturais e formação de quadros profissionais civis, militares e diplomáticos.

É possível que, com a nova Lei de Diretrizes e Bases da Educação (LDB), outras restrições comecem a existir. Já estão aprovadas pela Comissão de Educação da Câmara dos Deputados outras despesas que não poderão ser consideradas como de manutenção $\mathrm{e}$ desenvolvimento do ensino, como se pode ver a seguir:

- Pessoal docente e técnico-administrativo que esteja em desvio de função, como, por exemplo, professores que estão fora das salas de aula, funcionários que fazem serviços diferentes daqueles para os quais fizeram concurso ou foram contratados etc.

- Obras de infra-estrutura, mesmo quando ligadas diretamente às escolas, como, por exemplo, asfaltar a rua da escola e jogar as despesas como de manutenção e desenvolvimento do ensino. Ou outras "indecências" que vêm ocorrendo, como asfaltar o bairro, colocar água encanada e rede de esgoto para o bairro etc, e depois jogar as despesas na função educação, como se as obras tivessem sido feitas somente para a escola.

- Remanejamento de bens já computados como despesas de ensino para outras atividades diferentes. Por exemplo, é comum comprar uma frota de "peruas" para fazer o transporte dos alunos e depois, com o tempo, remanejá-las para outras secreta- 
rias. Ou então, comprá-las no mês de dezembro e vendê-las em janeiro. Se um bem for alocado e vendido, os recursos resultantes devem retornar novamente ao ensino.

- Despesas com programas suplementares (alimentação, saúde, material didático, transporte e assistência médica e psicológica dos alunos) não poderão ser computadas, para efeitos de cumprimento dos dispêndios mínimos da receita de impostos. O princípio adotado é o de financiar os programas suplementares com recursos de contribuições sociais e não com recursos dos impostos. A nova LDB, ao fazer essa restrição, propõe que $20 \%$ dos recursos do Finsocial passem novamente a financiar programas suplementares. Isto porque, com a Constituição Federal de 1988, os recursos do Finsocial e das loterias foi realocado exclusivamente para o Sistema de Seguridade Social. Ou se reconstitui a fonte anterior de financiamento, ou se cria nova fonte de recursos pela figura de uma nova contribuição social. Caso contrário, essa restrição tornar-se-á letra morta e os programas suplementares terão terão que ser financiados com os impostos.

- Despesas com hospitais universitários também deverão ser excluídas. Segundo nosso entendimento, um hospital universitário é uma escola. Com o tempo, é possível que esse hospital comece a atender à comunidade, fugindo de suas reais finalidades. A Lei de Diretrizes e Bases da Educação Nacional (LDB), nesse caso, deve considerar duas alternativas: incluir as despesas hospitalares ligadas ao ensino e excluir aquelas que digam respeito somente às situações que interessam exclusivamente à comunidade.

- Pesquisas realizadas por instituições não integrantes do sistema de ensino. Estava se tornando comum contratar instituições de pesquisa, de cunho privado, para fazer pesquisas com recursos públicos do ensino. Essa tendência, que se intensificava, vai ser coibida com esse dispositivo.

- Despesas com o pessoal inativo não serão mais consideradas. Isto significa que o pessoal inativo continuará a receber, continuará a previsão orçamentária pela educação e continuarão as despesas com as pensões e aposentadorias. O que não continua 
é a consideração dessas despesas como comprovação dos dispêndios mínimos da receita de impostos aplicada em educação. É uma questão que afeta a prestação de contas. O poder público vai ter que, além de financiar as porcentagens mínimas obrigatórias, financiar com mais recursos os inativos que prestaram serviços à educação.

Para terminar a lista das restrições que atingem a natureza das despesas, convém relembrar que a nova LDB condiciona a assistência técnica e financeira da União, em relação aos Estados, Distrito Federal e municípios, e a dos Estados, em relação a seus municípios, ao cumprimento de todos esses dispositivos.

Por último, neste item que trata de questões de planejamento e elaboração orçamentária, trataremos dos impostos a serem controlados nas três esferas do poder público.

0 sistema que vem a seguir decorre da Constituição Federal de 1988. Está dividido por esferas públicas e abrange impostos próprios e transferidos.

a) Esfera da União:

- Imposto de Importação de Produtos Estrangeiros (II);

- Imposto de Exportação para o exterior, de produtos nacionais ou nacionalizados (IE);

- Imposto de Renda e de proventos de qualquer natureza (IR);

- Imposto sobre Produtos Industrializados (IPI);

- Imposto sobre Operações Financeiras, incidente sobre operações de crédito, câmbio e seguro, ou relativas a títulos ou valores mobiliários (IOF);

- Imposto sobre a Propriedade Territorial Rural (IPTR);

- Imposto sobre Operações Financeiras, decorrentes de comercialização de ouro, entendido este como ativo financeiro ou instrumento cambial (IOF sobre ouro);

- Imposto sobre Grandes Fortunas (IGF).

b) Esfera dos Estados e do Distrito Federal:

- Imposto sobre Transmissão causa mortis e doação de quaisquer bens e direitos (ITCM); 
- Imposto sobre Operações relativas à Circulação de Mercadorias e sobre Prestações de Serviços de transporte interestadual e intermunicipal e de comunicação, ainda que as operações e as prestações se iniciem no exterior (ICMS);

- Imposto sobre a Propriedade de Veículos Automotores (IPVA);

- Imposto de Renda sobre lucros, ganhos e rendimentos de capital, com adicional de até $5 \%$ do que for pago à União por pessoas físicas ou jurídicas domiciliadas nos respectivos territórios;

- Imposto de Renda sobre o produto da arrecadação do Imposto da União sobre renda e proventos de qualquer natureza, incidentes na fonte, sobre rendimentos pagos, a qualquer título, por ele, suas autarquias e pelas fundações que instituírem e mantiverem;

- Imposto de Operações Financeiras sobre o ouro, entendido este como ativo financeiro ou instrumento cambial - 30\% da arrecadação federal (imposto transferido);

- Fundo de Ressarcimento das Exportações sobre produtos industrializados - $10 \%$ da arrecadação realizada pelo IPI federal (imposto transferido a ser regulamentado);

- Cota-parte do imposto sobre a renda e imposto sobre produtos industrializados - 21,5\% a ser integralizada em 1993 - e cota-parte do Fundo de Participação dos Estados e Distrito Federal (FPE).

c) Esfera dos municípios:

(IPTU);

- Imposto sobre a Propriedade Predial e Territorial Urbano

- Imposto sobre transmissão "inter vivos", a qualquer título, de bens imóveis (SISA);

- Imposto de Vendas a Varejo de Combustíveis Líquidos e Gasosos, exceto óleo diesel (IVV);

- Imposto sobre Serviços de Qualquer Natureza, excluídos os que sofrem a incidência do ICMS (ISS);

- Cota-parte da arrecadação federal do IR e do IPI, que 
formam o Fundo de Participação dos Municípios (FPM) - 22,5\% a serem integralizados em 1993;

- Arrecadação do IR incidente na fonte, de seus funcionários da administração direta, das autarquias e das fundações;

- Cota-parte do IPTR de origem federal $-50 \%$ de sua arrecadação;

- Cota-parte do IPVA de origem estadual - 50\% de sua arrecadação; arrecadação;

- Cota-parte do ICMS de origem estadual - $25 \%$ de sua

- Cota-parte do FRE, de origem federal, incidente em $25 \%$ dos $10 \%$ de origem estadual, que abrange o IPI federal (a ser regulamentado);

- Cota-parte da arrecadação do ouro enquanto ativo financeiro ou instrumento cambial, de origem federal $-70 \%$ de sua arrecadação para o município de origem.

Com base nesse rol de impostos próprios e transferidos, os impostos poderão ser controlados em seu montante. $\mathrm{O}$ dispêndio mínimo em educação incide sobre o montante desses impostos, próprios e transferidos.

\section{A sistemática da execução orçamentária}

Aprovado o orçamento como lei, o Poder Executivo tem que fazer um "quadro de quotas trimestrais das despesas que cada unidade orçamentária fica autorizada a utilizar" (Art. 47 da Lei $\mathrm{n}^{\circ}$ 4.320). O objetivo dessas quotas trimestrais é assegurar às unidades orçamentárias, em tempo útil, a soma de recursos necessários e suficientes para a melhor execução do seu programa anual de trabalho e manter, durante $o$ exercício, na medida do possível, o equilíbrio entre a receita arrecadada e a despesa realizada, de modo a reduzir ao mínimo eventuais insuficiências de tesouraria. Durante o exercício, as quotas trimestrais poderão ser alteradas. Todas as receitas deverão ser recolhidas a um caixa único, em estrita observância ao princípio de unidade de tesouraria. E todas as despesas devem ser empenhadas, isto é, o Esta- 
do, por ato emanado de autoridade competente, cria para si a obrigação de pagamento. É vedada a realização de despesas sem prévio empenho, a não ser em casos especiais fixados em legislação própria. Uma despesa somente pode ser paga se houver a nota de empenho correspondente, o contrato, o ajuste ou o acordo respectivo e os comprovantes da entrega do material ou da prestação efetiva do serviço. Somente após esse controle é que a ordem de pagamento pode ser expedida e, obrigatoriamente, processada pelo serviço de contabilidade. A despesa pública somente deve ser paga com cheque, por meio de estabelecimentos bancários, de preferência, oficiais. Somente em casos excepcionais poderão ser expedidos adiantamentos e geridos por órgãos centrais os recursos programados para as unidades orçamentárias. Tanto os casos de adiantamento quanto os de compra de materiais e serviços são regidos por legislação especial.

Com esses dados qualquer pessoa com uma formação básica poderá controlar a execução orçamentária. Merece destaque especial a necessidade de controlar os créditos adicionais que interferem na receita $\mathrm{e}$ na programação das quotas trimestrais.

São créditos adicionais as autorizações de despesa não computadas ou insuficientemente dotadas na Lei do Orçamento. Os créditos adicionais classificam-se em:

- suplementares, os destinados a reforço de dotação orçamentária já existente;

- especiais, os destinados a despesas para as quais não há dotação orçamentária específica;

- extraordinários, os destinados a despesas urgentes e imprevistas, em caso de guerra, comoção intempestiva ou calamidade pública

Os créditos orçamentários podem ser gerados por realoca-ções de rubricas ou por excesso de arrecadação, nos casos de serem suplementares e especiais. Nesses dois casos serão autorizados por lei e abertos por decreto executivo. Casos menos comuns são os de superávit financeiro, de anulação parcial ou total de dotação orçamentária e do produto de operações de crédito. So- 
mente podem ser abertos créditos adicionais quando houver disponibilidade financeira.

Merece destaque especial na execução orçamentária o excesso de arrecadação, isto é, o saldo positivo das diferenças acumuladas mês a mês, entre a arrecadação prevista e a realizada. Antes, o controle da arrecadação era muito difícil de ser feito por agentes externos ao órgão de arrecadação.

No entanto, a Constituição Federal de 1988 procurou resolver a questão:

Art. 162. A União, os Estados, o Distrito Federal e os municípios divulgarão, até o último dia do mês subseqüente ao da arrecadação, os montantes de cada um dos tributos arrecadados, os recursos recebidos, os valores de origem tributária entregues e a entregar e a expressão numérica dos critérios de rateio.

Parágrafo único. Os dados divulgados pela União serão discriminados por Estado e por município; os dos Estados, por município.

Em outras palavras, todas as esferas públicas têm, no máximo, 60 dias para divulgar os valores dos tributos arrecadados, imposto por imposto, taxa por taxa e contribuição por contribuição, além de outros recursos recebidos. Todas as transferências devem ser discriminadas, bem como os critérios utilizados para as mesmas. Além disso, os dados da União, tanto os de arrecadação como os de distribuição pelo sistema de transferência, serão discriminados Estado por Estado e município por município, e os dados dos Estados deverão ser discriminados município por município.

Este avanço, conquistado pela divulgação da arrecadação, permitirá estimar mais fidedignamente a receita do ano vindouro e calcular com exatidão o excesso ou déficit na arrecadação. Este sistema permite, com segurança, julgar se as transferências e os créditos adicionais estão sendo feitos com exatidão. Este princípio de divulgação independe de legislação estadual ou municipal; é de cumprimento obrigatório por todas as esferas públicas. 
A partir disso, qualquer cidadão, comissão, conselho ou órgão tem o instrumento efetivo de controle da arrecadação pública.

Como a educação vincula recursos mínimos dos impostos, fácil será controlar o percentual colocado no orçamento e nas complementações fragmentárias realizadas pelos créditos adicionais. Além disso, poderá haver uma atuação eficaz no que se refere ao disposto no $\S$ $4^{\circ}$ do Art. $4^{\circ}$ da Lei $n^{0} 7.348$, de 24 de julho de 1985, a saber:

As diferenças entre a receita e a despesa previstas e as efetivamente realizadas, que resultaram no não-atendimento dos percentuais mínimos obrigatórios, serão apuradas e corrigidas no último trimestre do exercício e, ainda havendo, no seu término, diferença, esta será compensada no exercício seguinte.

No caso da nova LDB, que ainda não sofreu a aprovação final, o $\S 4^{\circ}$ do Art. 107 obriga a fazer a correção da defasagem receita-despesa bimestralmente. E, no Art. 121, estabelece que "constitui responsabilidade das autoridades educacionais, nas diversas instâncias, o bom uso dos recursos públicos, respondendo as mesmas criminalmente, por sua má aplicação, malversação ou desperdício".

A seguir, convém reafirmar o texto constitucional em vigor, que estabelece no $\S 2^{9}$ do Art. 208 que "o não-oferecimento do ensino obrigatório pelo poder público, ou sua oferta irregular, importa responsabilidade da autoridade competente". Também, pelo inciso VI do Art.34, a União poderá intervir nos Estados e no Distrito Federal, e, pelo inciso III do Art. 35, os Estados poderão intervir nos municípios. O nãocumprimento da vinculação obrigatória para a educação pode gerar intervenção tanto no Estado quanto no município.

Talvez a questão mais substantiva da execução orçamentária seja a de fazer com que o dinheiro previsto no orçamento chegue às escolas, para a atividade-fim, não se perdendo nos meandros da burocracia. A execução orçamentária depende, em grande parte, da eficácia dos órgãos envolvidos no que se denomi- 
na de unidades de despesas. O ideal é que a unidade de despesa seja a própria escola, com exceção da verba para o pagamento de pessoal, e que critérios automáticos eliminem o arbítrio, que gera a politicagem na distribuição das verbas dentro do sistema de ensino. Somente uma política de desconcentração continuada fará com que as escolas sejam unidades de despesa e passem com maior agilidade a enfrentar os seus problemas.

\section{O controle social dos recursos financeiros públicos}

O que fizemos até aqui foi dar algumas informações básicas sobre questões que afetam a elaboração e a execução orçamentárias do poder público. O objetivo central, tal como já afirmamos, é o de criar as condições necessárias, em termos de informações, para que o controle social ou da sociedade se efetue de forma eficaz.

Como já descrevemos anteriormente, os sistemas internos e externos de controle são obrigatórios. O sistema interno, pelos órgãos contábeis, e o externo, pelo Tribunal de Contas e pelo Legislativo. No entanto, disposições legais foram, como passaremos a ver, exigindo, cada vez mais, a atuação dos órgãos envolvidos nos controles interno e externo.

Assim, a Lei $n^{0} 7.348 / 85$ determinou que os órgãos centrais dos sistemas de planejamento e orçamento e de administração financeira, contabilidade e auditoria, em suas áreas de atuação, estabelecerão mecanismos e meios de gerenciar, controlar e apurar os resultados que visem dar cumprimento aos dispêndios mínimos previstos na Constituição Federal para a educação.

Sobre a necessidade de quadro próprio para demonstrar o quantum e em quê vai se gastar em educação, a Lei ${ }^{\circ} 7.348 / 85$ determina que:

Os órgãos e entidades integrantes dos sistemas de planejamento e orçamento detalharão seus programas de trabalho, de modo que as ações, definidas nesta lei como de manutenção e desenvolvimento do ensino, sejam identificadas em seus aspectos

R. bras. Est. pedag., Brasília, v.72, n.172, p.262-290, set./dez. 1991 
operacionais, em níveis de subprojeto e subatividades orçamentários, para efeitos de consideração nas fases da elaboração e execução do orçamento.

A referida lei ainda estabelece que "no $1^{0}$ (primeiro) ano da publicação desta lei, deverão a União, os Estados, o Distrito Federal e os municípios, por seu Poder Executivo, ajustar os respectivos orçamentos às normas aqui fixadas."

A nova LDB aprofunda as questões aqui vistas, envolvendo um grande número de outros órgãos. Assim, no Art. 110, envolve também os Tribunais de Contas no controle dos dispêndios mínimos obrigatórios em educação. No $\S 1^{\circ}$ do Art. 110, determina que "as ações de manutenção e desenvolvimento do ensino serão identificadas nas Leis de Diretrizes Orçamentárias e nos orçamentos das diferentes esferas administrativas, devendo estes conter anexos discriminatórios dos projetos e atividades correspondentes e da receita constitucionalmente vinculada".

No $\S 2^{\circ}$ desse mesmo artigo está dito que "as despesas com a manutenção e o desenvolvimento do ensino serão apuradas e publicadas nos balanços do poder público, assim como nos relatórios a que se refere o Art. 165, § $3^{\circ}$, da Constituição. O Art. 165, § $3^{\circ}$, da Constituição, estabelece que "o Poder Executivo publicará, até 30 dias após o encerramento de cada bimestre, relatório resumido da execução orçamentária". No $\S 3^{\circ}$ do Art. 110 da nova LDB ainda se estabelece que "a mensagem anual do chefe do Poder Executivo ao Poder Legislativo incluirá relatório sobre o que foi realizado no período em cumprimento ao Art.212 da Constituição (vinculação obrigatória de recursos) e ao disposto nesta lei".

Em seu Art. 113, a nova LDB ainda reza que:

... cabe às Comissões de Educação, de Finanças e de Orçamento da Câmara dos Deputados e do Senado Federal, aos ministros de Estado, responsáveis pelas áreas de Educação e da Economia, e ao Conselho Nacional de Educação exigir o cumprimento, pelos meios a seu alcance, do disposto neste capítulo, especialmente quanto à aplicação mínima em educação e sua devida divulgação. 
$\S 1^{\circ}$. A divulgação da aplicação em educação, de responsabilidade do Poder Executivo, incluirá a relação nominal dos montantes destinados a instituições privadas, de fins não-lucra-tivos, e os destinados a bolsas de estudo.

$\S 2^{\circ}$. Nos Estados, Distrito Federal e municípios, as responsabilidades definidas no $\S 1^{\circ}$ caberão aos órgãos correspondentes nas respectivas esferas.

Portanto, há um arsenal de dispositivos que permitem, agora, controlar os recursos financeiros que vão ser gastos ou foram gastos em educação.

Como se disse no início deste trabalho, qualquer cidadão, através de ação popular, pode constranger o poder público a cumprir a Lei.

A nação está à espera desses abnegados que atuem, isoladamente ou em grupos organizados, para fazer valer a lei, para fazer com que a educação não seja privilégio de poucos, mas que seja o instrumento de salvação de todos e da sociedade contra a ignorância. Uma sociedade educada provavelmente será uma sociedade mais crítica, mais competente, mais produtiva, mais justa e mais feliz. A gestão mais democrática e transparente dos recursos aplicados em educação é um dos fatores que podem ajudar o País a caminhar nessa direção.

Resumo e conclusões

Este trabalho é o fruto de uma série de reflexões que fizemos quando pronunciamos algumas conferências para a União Nacional de Dirigentes Municipais da Educação (Undime), composta por Secretários da Educação das Regiões Nordeste, Centro-Oeste, Sul e Sudeste, e para a Fundação para o Desenvolvimento da Administração Pública (Fundap), composta por membros das Comissões de Educação dos municípios, durante o segundo semestre de 1990.

Procuramos fornecer dados para se entender:

1. A experiência de envolvimento da sociedade local em

R bras. Est. pedag., Brasília, v.72, n.172, p.262-290, set./dez. 1991 
problemas e soluções afetas à educação nos municípios do Estado de São Paulo.

2. O processo de planejamento público e a elaboração orçamentária, com destaque para os recursos educacionais que exigem, praticamente, um novo quadro ou classificação orçamentária. São levantadas questões de elaboração orçamentária relacionadas com a receita, sua estimativa e o rol de impostos próprios e transferidos que devem sofrer a incidência dos percentuais mínimos e obrigatórios vinculados à educação. Trata, ainda, das despesas integradas no orçamento-programa e na técnica do seu detalhamento. A par dessas questões mais importantes, são tratadas as diversas classificações orçamentárias e algumas noções sobre tipos de orçamento, existentes aqui e em outros países.

3. A execução orçamentária e o sistema de controle das despesas públicas. Assim, são citados diversos mecanismos para o controle da arrecadação de impostos e de despesas, como, por exemplo, as quotas trimestrais. Deu-se destaque às questões que envolvem os créditos adicionais, que vão sendo aprovados durante o ano.

4. O controle que se pode fazer dos recursos financeiros públicos aplicados à educação. Aqui deu-se destaque para os diversos órgãos controladores, com suas competências e obrigações, do que é atualmente obrigatório e do que, no futuro, passará a ser, quando a nova LDB for aprovada em instância final. Deu-se destaque ao controle social que poderá ser feito por indivíduos isolados ou organizados em grupos representativos da sociedade civil.

5. Nas conclusões, procuramos resumir os aspectos mais importantes das diferentes partes.

Para finalizar, este trabalho é mais um estudo que proporcionamos aos educadores que se preocupam com a gestão democrática dos recursos públicos. São informações que podem aumentar o nível de intervenção dos interessados em fazer com que os recursos educacionais sejam geridos em benefício da maioria da população de forma mais democrática e transparente. 


\section{Referências bibliográficas}

BRASIL. Congresso. Câmara dos Deputados. Comissão de Educação. Anteprojeto da nova Lei de Diretrizes e Bases da Educação Nacional, aprovado pela Comissão de Educação da Câmara dos Deputados em 28 de junho de 1990. Brasília, 1990.

BRASIL. Constituição, 1988. Constituição da República Federativa do Brasil1988. Brasília: Cegraf, 1988.

BRASIL. Lei n ${ }^{9}$ 4.320, de 17 de março de 1964.

BRASIL. Lei $n^{9}$ 7.348, de 24 de julho de 1985.

SÃO PAULO (estado). Constituição, 1989. Constituição do Estado de São Paulo1989.

SAO PAULO (estado). Decreto $n^{9} 30.375$, de 13 de setembro de 1989.

SÃO PAULO (estado). Decreto n 32.392, de 24 de setembro de 1990.

Recebido em 4 de fevereiro de 1991

José Carlos de Araújo Melchior, doutor em Financiamento da Educação, é professor titular do Departamento de Administração em Economia da Educação da Universidade de São Paulo (USP).

This study approacches the administration of public resources in Brazil, from the point of view of the administrative process, comprising planning, accomplishment and the social control of the financial public resources. It aims also at extending the concept of democratic management through participation of the concerned in the decision-making institutions. It focus some alternatives to enable any citizen to participate in the educational process and, similarly, in other activities sectors performed by the Public Power, providing instruments for interventions in budgetary issues (revenue and expenses) from institutions linked to management of financial resources of the education

R. bras. Est. pedag., Brasília, v.72, n.172, p.262-290, set./dez. 1991 
sector. The paper has been organized in five parts: 1) the experience in São Paulo state; 2) the public planning systematic; 3) the budgetary performance systematic; 4) social control of public financial resources; 5) conclusions.

Cet article discute la gestion démocratique des ressources publiques au Brésil, sous la perspective du procés administratif, comprenant la planification, l'exécution et le controle social des ressources financières publiques. Il prétend aussi grandir la conception selon laquelle Ia gestion démocratique est possible par la voie exclusive de la participation des intéressés dans les organismes de décision. On présent des alternatives qui peuvent conduire un citoyen quelconque à participer de ce procés en éducation, et par extension, aux autres domaines d'activités pratiquées par le pouvoir public, donnant desoutils pour une intervention à la receite et aux frais du secteur public chargé d'administrer les ressources financières destinées à 1'éducation. Le travail est divisé en cinq parties: 1) 1'expèrience à l'Etat de São Paulo; 2) Ia systématique de Ia planification publique; 3) la systématique de l'exécution budgétaire; 4) le contrôle social des ressources financières publiques et 5) conclusiones.

Aborda la gestión democrática de los recursos públicos en el Brasil, bajo Ia perspectiva del proceso administrativo, incluye la Planificación, la ejecución y el control social de los recursos financieros públicos. Pretende aún ampliair Ia Concepción de que la gestión democrática se da por Ia via exclusiva de la participación de los interresados en los órganos de decisión. Son enfocadas alternativas que pueden llevar a cualquier ciudadano a participar de ese proceso de educación y, por extensión, en los demás sectores de actividades ejercidas por el poder público, proporcionando instrumentos para una intervención en el haber $y$ en el gasto del sector público encargado de administrar los recursos financieros designados para educación. El trabajo se divide en cinco partes: 1) Ia experiencia en Estado de são Paulo: 2) la sistemática de Ia Planificación pública: 3) Ia sistemática de la ejecución presupuestaria; 4) el control social de los recursos financieros públicos y 5) Ias conclusiones. 